\title{
Hepatectomy plus adjuvant transcatheter arterial chemoembolization improves the survival rate of patients with multicentric occurrence of hepatocellular carcinoma
}

\author{
DA XU*, XIAOFENG LIU*, LIJUN WANG and BAOCAI XING
}

Key Laboratory of Carcinogenesis and Translational Research (Ministry of Education/Beijing), Hepatopancreatobiliary Surgery Department I, Peking University Cancer Hospital and Institute, Beijing 100142, P.R. China

Received September 5, 2017; Accepted June 29, 2018

DOI: $10.3892 / 01.2018 .9333$

\begin{abstract}
The aim of the present study was to evaluate the role of hepatectomy plus adjuvant transcatheter arterial chemoembolization (TACE) in patients with multicentric occurrence (MO) or intrahepatic metastases (IM) of hepatocellular carcinoma (HCC). Patients with multifocal HCC who underwent hepatic resection only (HR) or HR plus adjuvant TACE (HRT) between January 2005 and December 2015 were divided into MO or IM groups. The patient characteristics and outcomes were retrospectively analyzed. A total of 103 patients (59 and 44 in the MO and IM groups, respectively) were included in the analysis. The 1-, 3- and 5-year overall survival (OS) rates were 92.7, 76.8 and 56.8\% for the MO group, and 93.1, 41.6 and $18.5 \%$ for the IM group, respectively (OS, $\mathrm{P}=0.001$ ), and the $1-, 3$ - and 5 -year disease-free survival (DFS) rates were 84.1, 44.6 and 40.5\% for the MO group and 51.7, 22.5 and 15.0\% for the IM group, respectively (DFS, $\mathrm{P}<0.001$ ). In the subgroup analysis, the overall survival were significantly better in the MO-HRT group compared with those in the MO-HR group $(\mathrm{P}=0.019)$, which was also observed between the IM-HRT and IM-HR groups $(\mathrm{P}=0.132)$. Furthermore, the 1-, 3- and 5-year OS demonstrated non-significant differences between patients with $<3$ and $\geq 3$ tumors in the MO-HR group $(\mathrm{P}=0.300)$, but significantly reduced OS for patients with $\geq 3$ tumors in the IM-HR group compared with that for patients with $<3$ tumors $(\mathrm{P}=0.132)$. In conclusion, surgical resection combined with
\end{abstract}

Correspondence to: Professor Baocai Xing, Key Laboratory of Carcinogenesis and Translational Research (Ministry of Education/Beijing), Hepatopancreatobiliary Surgery Department I, Peking University Cancer Hospital and Institute, 52 Fucheng Road, Beijing 100142, P.R. China

E-mail: xingbaocai88@sina.com

*Contributed equally

Key words: hepatocellular carcinoma, multicentric occurrence, intrahepatic metastases, hepatic resection, transcatheter arterial chemoembolization, survival adjuvant TACE may result in significantly increased survival rates of patients with MO-HCC. Tumor number should not be an absolute contradiction to hepatectomy in patients with MO-HCC.

\section{Introduction}

Hepatocellular carcinoma (HCC) is a common malignancy globally and the third most common cause of cancer-associated mortality $(1,2)$. Surgery has become the primary treatment for HCC, with a 5-year overall survival (OS) rate of $40-50 \%(3,4)$. Furthermore, $>50 \%$ of patients with HCC are initially diagnosed with multiple tumors (5), reducing the probability of receiving successful treatment for cases that exceed the Barcelona Clinic Liver Cancer (BCLC) staging system for radical hepatectomy, due to its high recurrence rate following surgery $(6,7)$; however, a previous study determined that not all patients with multinodular HCC of an intermediate stage would experience poor long-term survival following surgical resection (8). Multiple HCC lesions may originate differently from multicentric occurrence (MO) or intrahepatic metastases (IM), which have dissimilar outcomes (9). The origin of MO-HCC is different from the primary lesion, while IM-HCC is derived from the primary tumor. A number of methods and features are used to differentiate MO-HCC from IM-HCC, including tumor location, satellite tumors, growth from portal tumor emboli or histological grading $(10,11)$. In previous studies, patients with MO-HCC were reported to have an improved outcome compared with patients with IM-HCC following hepatectomy $(12,13)$; thus, determining the origin of multifocal HCC may benefit the selection of patients for radical surgery. Additionally, a number of studies also determined that adjuvant transcatheter arterial chemoembolization (TACE) may be beneficial in prolonging the survival of patients with high-risk HCC, including those with larger size, multinodular tumors and microvascular invasion (14-16); however, the current literature does not indicate the type of multifocal HCC that may benefit from adjuvant TACE. The present study was conducted to investigate the survival benefits for patients with MO-HCC or IM-HCC who underwent liver resection and subsequent adjuvant TACE. 


\section{Materials and methods}

Selection of patients. A total of 871 patients with pathologically-confirmed HCC underwent hepatectomy between January 2005 and December 2015 in Hepatopancreatobiliary Surgery Department I at the Peking University Cancer Hospital and Institute (Beijing, China). The study design was approved by the Ethical Review Board Committee of the Beijing Cancer Hospital and Institute (Beijing, China). A total of 107 patients (12.3\%) were pathologically diagnosed with multinodular HCC. A total of 4 patients were excluded. Finally, 103 patients were included in the present study, including 89 men and 14 women, with a median age of 57 years (range, 25-78 years). According to the aforementioned clinicopathological determination criteria, 59 cases were included in the MO group and 44 cases were included in the IM group. In the MO-HCC subgroup, 22 patients received hepatic resection (HR) only (MO-HR), and 37 patients received HR plus adjuvant TACE (HRT) (MO-HRT). The pathological stage of each nodular was reviewed and recorded in the resected specimens by two senior pathologists in a blinded manner using the Edmondson-Steiner staging method (6). The demographic, surgical, pathological and survival data of all patients were collected and analyzed. The inclusion criterion included the multinodular lesions being pathologically confirmed as HCC. The exclusion criteria included the following: i) Mixed HCC or cholangiocellular carcinoma; ii) emergence of extrahepatic metastasis; iii) no R0 resection; and iv) existence of another type of primary tumor.

Differentiation criteria for $\mathrm{MO}$ and IM of multinodular HCC. A number of studies have examined the differences between IM and MO (10-12,17). The differentiation criteria described in the present study are based on the Liver Cancer Study Group criteria (Japanese Society of HCC criteria) (18). IM-HCC is defined based on the following: i) Tumor cases that appear to have developed from or on the basis of portal tumor emboli; ii) a large primary tumor with multiple satellite nodules; and iii) all tumors are histologically similar. MO-HCC is defined based on the following: i) Each tumor occurs separately in a different hepatic segment; and ii) the multiple tumors have different histological grading of well-differentiated and moderately or poorly differentiated HCC (pathological heterogeneity) $(10,11,19)$.

Surgery. Tumor cases were confirmed using contrast-enhanced computed tomography (CT) or magnetic resonance imaging with vascular contrast agents. A number of patients were also assessed using contrast-enhanced ultrasonography. Liver function tests were performed prior to the surgery, including tests for albumin, bilirubin, blood coagulation function and 15-min indocyanine green clearance. Only patients with well-preserved liver function (Child-Pugh grade A) and good performance status, with an estimated residual liver volume $>40 \%$, underwent HR. Patients with hepatitis B infection were treated with antiviral drugs at least 1 week prior to surgery. Liver transections were primarily performed using the clamp method with a Peng multifunctional operative dissector [Hangzhou Shuyou Medical Instrument Co., Ltd., Hangzhou, China; FDA catalog no. 510(K), K040780]. An intermittent
Pringle maneuver was used during liver transection. Vascular invasion was diagnosed if vascular involvement or tumor invasion was confirmed by imaging or pathological studies. Hepatic resection was performed using anatomical liver resection or partial liver resection. Resection was considered as major when $\geq 3$ liver segments were removed and as minor when $<3$ liver segments or partial liver parenchyma were removed.

Postsurgical outcomes and follow-up. Postsurgical mortality was defined as mortality within 30 days of surgery. Grade III or higher adverse events were considered major complications, while Grade I-II adverse events were defined as minor complications. Postsurgical hepatic insufficiency was defined according to the International Study Group of Liver Surgery consensus (20).

Contrast-enhanced CT or magnetic resonance imaging, chest radiography, liver function tests and measurements of serum $\alpha$-fetoprotein levels were performed 4 weeks after surgery, and every 3 months thereafter. Tumor recurrences were treated with liver resection, radiofrequency ablation or TACE. Only 13 patients did not receive the treatment following recurrence due to a fast recurrence of the tumor (within 3 months) or severe liver cirrhosis and liver failure.

Adjuvant TACE. Adjuvant TACE (2 cycles) was suggested to all patients with multinodular HCC by the attending physician $\sim 4$ weeks after surgery, when the liver function had recovered. Whether patients followed the recommendations of the physician primarily depended on their socioeconomic status or wishes; therefore, adjuvant TACE was not performed in all patients, with those who refused receiving hepatic resection only. The Seldinger technique was performed to place a hepatic arterial catheter into the proper hepatic artery via the femoral artery, with the patient under local anesthesia. Hepatic angiography or CT angiography was performed to detect any notable tumor stains in the remnant liver. Oxaliplatin $(150 \mathrm{mg})$ and leucovorin $(150 \mathrm{mg}$ ) were infused, and fluorouracil $\left(1,500 \mathrm{mg} / \mathrm{m}^{2}\right)$ was continuously pumped (for $24 \mathrm{~h}$ ) through the catheter. The dosage was determined by the body surface area and underlying liver function. At the 1-month follow-up, a CT scan was obtained to determine the effects of TACE.

Study endpoints. The primary endpoint of the study was to evaluate 1,3 and 5-year OS and disease-free survival (DFS) rates in the IM and $\mathrm{MO}$ groups. The secondary endpoint was to evaluate the OS benefits and safety of hepatectomy plus postsurgical adjuvant TACE. The tertiary endpoint was to identify whether tumor number was a prognostic factor affecting the staging and long-term outcomes of multinodular HCC.

Statistical analysis. Continuous variables are presented as the mean \pm standard deviations or medians with interquartile ranges, and discreet variables are presented as numbers with percentages. Categorical variables were compared using the $\chi^{2}$ test, and continuous variables were compared using a Student's t-test or non-parametric Mann-Whitney U test. Survival rates were obtained by the Kaplan-Meier method and were compared using the log-rank test. OS and DFS were calculated from the date of hepatectomy to the time of 


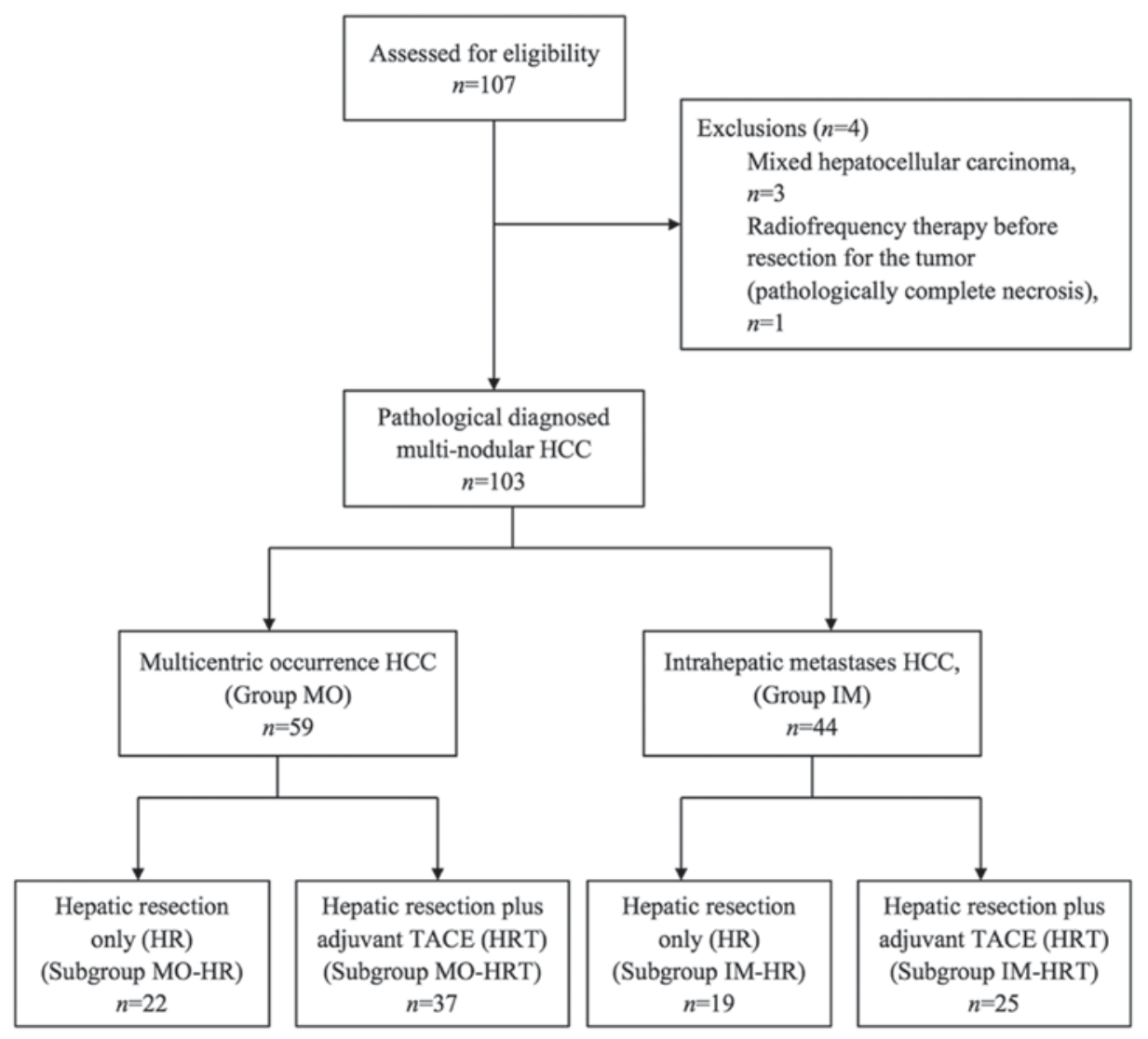

Figure 1. Study flowchart. HCC, hepatocellular carcinoma; TACE, transcatheter arterial chemoembolization; MO, multicentric occurrence; IM, intrahepatic metastases; HR, hepatic resection; HRT, HR plus adjuvant TACE.

mortality/recurrence or the last time of follow-up. Variables that were statistically significant in the univariate analysis $(\mathrm{P}<0.05)$ were included in the multivariate analysis using a Cox proportional hazards model. All patients were followed up until mortality or until June 1,2016 . $\mathrm{P}<0.05$ was considered to indicate a statistically significant difference. The analysis was performed using SPSS version 21.0 statistical software (IBM Corp., Armonk, NY, USA).

\section{Results}

Grouping based on clinicopathologicalfeatures. The flowchart for the present study is depicted in Fig. 1. In total, 107 patients with multinodular tumors who underwent liver resection with or without adjuvant TACE were evaluated. A total of 4 patients were excluded, including 3 patients with mixed HCC and 1 patient who received radiofrequency therapy prior to tumor resection; subsequently, the tumor was pathologically demonstrated to have undergone complete necrosis. None of the patients were lost to follow-up, thus 103 patients were included in the present study, including 89 men and 14 women, with a median age of 57 years (range, 25-78 years). According to the aforementioned clinicopathological determination criteria, 59 cases were included in the MO group and 44 cases were included in the IM group for further analysis.

Clinicopathological and surgical features of the patients. For further analysis, the clinicopathological variables of the two groups were investigated (Table I). Tumor size (the largest tumor in one patient) $(\mathrm{P}=0.008)$, portal tumor emboli $(\mathrm{P}=0.031)$, pathological heterogeneity $(\mathrm{P}=0.002)$, location of segment and satellite tumors $(\mathrm{P}<0.001)$ differed significantly between the two groups. The surgical outcomes and postsurgical treatments are presented in Table II. There were no significant differences in surgical time, surgical blood loss or type of surgery between the two groups. Surgical morbidities, including hepatic insufficiency, ascites and biliary fistula, and the proportion of patients receiving adjuvant therapy were also similar between the two groups.

Survival analysis. The median duration of follow-up was 34 months (range, 5-123 months) for the MO group and 25 months (range, 3-49 months) for the IM group. The Kaplan-Meier survival curves for the two groups are depicted in Fig. 2. The 1-, 3- and 5-year OS rates were 92.7, 76.8 and $56.8 \%$, respectively, for the MO group, and 93.1, 41.6 and $18.5 \%$, respectively, for the IM group ( $\mathrm{P}=0.001$; Fig. $2 \mathrm{~A})$. The 1-, 3- and 5-year DFS rates were 84.1, 44.6 and $40.5 \%$, respectively, for the MO group, and 51.7, 22.5 and $15.0 \%$, respectively, for the IM group $(\mathrm{P}<0.001$; Fig. $2 \mathrm{~B})$. There was a significant difference between the two groups in terms of DFS and OS. Multivariate Cox proportional hazards regression analyses identified $>2$ tumors, no adjuvant TACE and IM-HCC as independent prognostic factors for OS in patients with multifocal HCC (Table III).

Subgroup analysis by treatment method. Patients with multifocal HCC were further classified according to whether 
Table I. Patient demographic and clinicopathological characteristics.

\begin{tabular}{|c|c|c|c|}
\hline Characteristics & MO-HCC (n=59) & IM-HCC (n=44) & P-value \\
\hline Age, years & & & 0.245 \\
\hline Mean \pm SD & $57.05 \pm 8.39$ & $54.84 \pm 10.81$ & \\
\hline Sex, n (\%) & & & 0.773 \\
\hline Male & $50(84.7)$ & $39(88.6)$ & \\
\hline Female & $9(15.3)$ & $5(11.4)$ & \\
\hline Albumin, $\mathrm{g} / \mathrm{l}$ & & & 0.529 \\
\hline Mean \pm SD & $44.31 \pm 3.74$ & $43.80 \pm 4.44$ & \\
\hline Total bilirubin, $\mu \mathrm{mol} / 1$ & & & 0.991 \\
\hline Median (IQR) & $14.80(8.30)$ & $14.80(7.95)$ & \\
\hline Platelet count, $\mathrm{x} 10^{9} / 1$ & & & 0.736 \\
\hline Median (IQR) & $126(60)$ & $130(67.75)$ & \\
\hline Prothrombin time, $\mathrm{s}$ & & & 0.472 \\
\hline Median (IQR) & $11.90(1.30)$ & $11.65(1.15)$ & \\
\hline Liver cirrhosis, n (\%) & & & 1.000 \\
\hline Yes & $57(96.6)$ & $42(95.5)$ & \\
\hline No & $2(3.4)$ & $2(4.5)$ & \\
\hline Underlying hepatitis, n (\%) & & & 0.223 \\
\hline HBV & $50(84.7)$ & $40(90.9)$ & \\
\hline $\mathrm{HCV}$ & $5(8.5)$ & $0(0.0)$ & \\
\hline Both & $3(5.1)$ & $2(4.5)$ & \\
\hline None & $1(1.7)$ & $2(4.5)$ & \\
\hline Tumor number, n (\%) & & & $<0.001^{\mathrm{a}}$ \\
\hline 2 & $52(88.1)$ & $21(47.7)$ & \\
\hline$>2$ & 7 (11.9) & $23(52.3)$ & \\
\hline Tumor size (largest tumor), mm & & & $0.008^{\mathrm{a}}$ \\
\hline Median (IQR) & $38.0(38.0)$ & $56.5(43.0)$ & \\
\hline Tumor size (second largest tumor), mm & & & 0.328 \\
\hline Median (IQR) & $15.0(20.0)$ & $12.0(15.0)$ & \\
\hline AFP, ng/ml & & & 0.622 \\
\hline Median (IQR) & $21.83(306.95)$ & $35.35(686.17)$ & \\
\hline Microvascular invasion, n (\%) & & & 0.051 \\
\hline Yes & $13(22.0)$ & $18(40.9)$ & \\
\hline No & $46(78.0)$ & $26(59.1)$ & \\
\hline Portal tumor emboli, n (\%) & & & $0.031^{\mathrm{a}}$ \\
\hline Yes & $0(0.0)$ & $4(9.1)$ & \\
\hline No & $59(100.0)$ & $40(90.9)$ & \\
\hline Edmonson grade, $\mathrm{n}$ & & & 0.866 \\
\hline $\mathrm{I}$ & 6 & 4 & \\
\hline II & 37 & 30 & \\
\hline III & 16 & 10 & \\
\hline Pathological heterogeneity, n (\%) & & & $0.002^{\mathrm{a}}$ \\
\hline Yes & $40(81.6)$ & $41(93.2)$ & \\
\hline No & $19(18.4)$ & $3(6.8)$ & \\
\hline Location of segment, n (\%) & & & $<0.001^{\mathrm{a}}$ \\
\hline Same & $10(16.9)$ & $32(72.7)$ & \\
\hline Different & $49(83.1)$ & $12(27.2)$ & \\
\hline Satellite tumors, n (\%) & & & $<0.001^{\mathrm{a}}$ \\
\hline Yes & $58(98.3)$ & $22(50.0)$ & \\
\hline No & $1(1.7)$ & $22(50.0)$ & \\
\hline
\end{tabular}

${ }^{\mathrm{a}} \mathrm{P}<0.05$. MO, multicentric occurrence hepatocellular carcinoma; IM, intrahepatic metastases hepatocellular carcinoma; AFP, $\alpha$-fetoprotein; $\mathrm{SD}$, standard deviation; IQR, interquartile range; HBV, hepatitis B virus; $\mathrm{HCV}$, hepatitis $\mathrm{C}$ virus. 
Table II. Surgical and postsurgical treatment.

\begin{tabular}{lccc}
\hline Variables & $\begin{array}{c}\text { MO } \\
(\mathrm{n}=59)\end{array}$ & $\begin{array}{c}\text { IM } \\
(\mathrm{n}=44)\end{array}$ & P-value \\
\hline $\begin{array}{l}\text { Surgical time, min } \\
\text { Mean } \pm \text { SD }\end{array}$ & $167.1 \pm 50.1$ & $176.1 \pm 8.5$ & 0.393 \\
$\begin{array}{l}\text { Surgical blood loss, ml } \\
\quad \text { Median (IQR) }\end{array}$ & $200(300)$ & $200(287.5)$ & 0.332 \\
$\quad \begin{array}{l}\text { Type of surgery, n (\%) } \\
\text { Minor }\end{array}$ & $42(71.2)$ & $23(52.3)$ & \\
$\quad$ Major & $17(28.8)$ & $21(47.7)$ & \\
Surgical morbidities, $\mathrm{n}(\%)^{\mathrm{a}}$ & $8(13.55)$ & $8(18.2)$ & 0.827 \\
$\quad$ Hepatic insufficiency & $5(8.5)$ & $7(15.9)$ & 0.353 \\
Biliary fistula & $3(5.1)$ & $1(2.3)$ & 0.634 \\
Adjuvant TACE, n (\%) & & & 0.684 \\
$\quad$ Yes & $37(62.7)$ & $25(56.8)$ & \\
No & $22(37.3)$ & $19(43.2)$ & \\
\hline
\end{tabular}

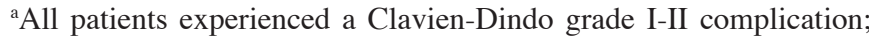
no Grade III or higher complications or postsurgical mortality occurred. MO, multicentric occurrence hepatocellular carcinoma; IM, intrahepatic metastases hepatocellular carcinoma; TACE, transcatheter arterial chemoembolization; SD, standard deviation; IQR, interquartile range.

they underwent HR only or HRT. In the MO-HCC subgroup, 22 patients received HR only (MO-HR), and 37 patients received HRT (MO-HRT). The Kaplan-Meier survival curves for the patients are depicted in Fig. 3. The 1-, 3- and 5-year OS rates were $97.1,86.8$ and $73.2 \%$, respectively, for the MO-HRT group, and 85.2, 60.1 and $28.0 \%$, respectively, for the MO-HR group $(\mathrm{P}=0.019$; Fig. 3A), and there was a significant difference between the two groups. Multivariate Cox proportional hazards regression analyses identified no adjuvant TACE as an independent prognostic factor for OS in patients with MO-HCC (Table IV). In the IM-HCC subgroup, 19 patients received HR only (IM-HR), and 25 patients received HRT (IM-HRT). The 1-, 3- and 5-year OS rates were 100.0,46.6 and $25.9 \%$, respectively, for the IM-HRT group, and 84.2, 38.3 and $25.5 \%$, respectively, for the IM-HR group ( $\mathrm{P}=0.132$; Fig. $3 \mathrm{~B})$, with no significant difference between the two groups.

Subgroup analysis by tumor number. In order to verify whether tumor number is a prognostic factor affecting the staging and treatment of multinodular HCC, the patients were classified according to whether they had $<3$ or $\geq 3$ tumors (Table V). The Kaplan-Meier survival curves for the patients are depicted in Fig. 4. In the MO-HCC subgroup, 52 patients had $<3$ tumors and 7 patients had $\geq 3$ tumors. The 1-, 3- and 5-year OS rates were $100.0,60.0$ and $30.0 \%$, respectively, for the MO-HCC subgroup with $<3$ tumors, and 91.8, 78.7 and $59.8 \%$, respectively, for the MO-HCC subgroup with $\geq 3$ tumors ( $\mathrm{P}=0.300$; Fig. 4A). There was no significant difference between the two groups. Additionally, 21 patients with IM-HCC had $<3$ tumors and 23 patients with IM-HCC had $\geq 3$ tumors. The 1-, 3 - and 5 -year OS rates were $95.2,88.4$ and $25.8 \%$, respectively, for the
IM-HCC subgroup with $<3$ tumors, and 86.5, 52.1 and $24.3 \%$, respectively, for patients with $\geq 3$ tumors ( $\mathrm{P}=0.022$; Fig. 4B). There was a significant difference between the two groups.

\section{Discussion}

Multifocal tumors are common in HCC $(21,22)$. A previous survey demonstrated that approximately half of all patients with HCC are diagnosed with multiple lesions (23). Despite advances in resection and ablation techniques, the recurrence rate following initial treatment remains high, and the prognosis of patients with multifocal HCC following surgical resection is generally unfavorable $(24,25)$. According to BCLC staging, palliative treatment, including TACE, in the only appropriate treatment option for the majority of patients with multifocal HCC, with a median survival time of $<20$ months and a 5 -year survival rate of 6-20\% (26).

Currently, it is accepted that multifocal HCC may be classified into two types: IM and MO $(27,28)$. IM-HCC is primarily considered as a metastatic lesion from the central tumor; therefore, tumor cases are frequently at an advanced stage, and the prognosis is generally unfavorable. By contrast, MO-HCC tumors are derived independently from each other, resulting in an improved prognosis compared with that of metastatic disease. Therefore, it is important to distinguish between these two tumor types. As early as the 1990s, surgeons distinguished IM-HCC from MO-HCC primarily using clinicopathological features $(13,17,29)$. In the present study, patients were classified with multifocal HCC according to the Japanese Society of $\mathrm{HCC}$ criteria, and it was determined that $57 \%$ were patients with MO-HCC, which is similar to the results of a previous study (13). Portal tumor emboli, pathological heterogeneity, location of segments and satellite tumors differed significantly between the two groups, which is consistent with the differentiation criteria for IM and MO. Previously, a number of other approaches have been developed to differentiate between these two HCC types, including profiling of integrated hepatitis B virus (HBV) DNA by polymerase chain reaction and southern blotting, loss of heterozygosity analysis of specific microsatellite loci and next-generation sequencing $(28,30,31)$. In a previous study, seven candidate genes with notable differential expression in 2 patients were selected and validation studies were performed using paired tumor/non-tumor tissues from 174 patients with HBV-HCC. Subsequently, the expression of threonine and tyrosine kinase was identified as a novel adverse prognostic factor of HBV-HCC (28). Furthermore, clinicopathological features are the most convenient method to distinguish between the two types of multifocal HCC. Using this criteria, it was determined that patients with MO-HCC have an improved benefit (5-year OS rate of $56.8 \%$ and a DFS rate of $40.5 \%$ ) from liver resection compared with that of patients with IM-HCC (5-year OS rate of $18.5 \%$ and a DFS rate of $15.0 \%$ ). Multivariate analyses identified IM-HCC as an independent prognostic factor for OS in patients with multifocal HCC. Additionally, surgery for IM and MO was not associated with increased surgical time or blood loss. All surgical morbidities were Clavien-Dindo grade I and II, indicating that surgical resection for multinodular HCC is a safe treatment option. This result is consistent with that of a previous study (32). 
Table III. Univariate and multivariate Cox proportional hazards regression analyses of factors associated with overall survival of patients $(\mathrm{n}=103)$ with multinodular hepatocellular carcinoma.

\begin{tabular}{|c|c|c|c|}
\hline \multirow[b]{2}{*}{ Factor } & \multirow{2}{*}{$\frac{\text { Univariate }}{\text { P-value }}$} & \multicolumn{2}{|c|}{ Multivariate analysis } \\
\hline & & $\operatorname{HR}(95 \% \mathrm{CI})$ & P-value \\
\hline Tumor number $(2 />2)$ & $<0.001^{\mathrm{a}}$ & $2.985(1.425-6.251)$ & $0.004^{\mathrm{a}}$ \\
\hline Tumor size $(<50 / \geq 50 \mathrm{~mm})$ & 0.215 & & \\
\hline $\operatorname{AFP}(<100 / \geq 100 \mathrm{ng} / \mathrm{ml})$ & 0.144 & & \\
\hline Microvascular invasion (no/yes) & 0.102 & & \\
\hline Portal tumor emboli (no/yes) & 0.639 & & \\
\hline Liver cirrhosis (no/yes) & 0.652 & & \\
\hline $\mathrm{MO} / \mathrm{IM}$ & $<0.001^{\mathrm{a}}$ & $2.311(1.087-4.914)$ & $0.031^{\mathrm{a}}$ \\
\hline Adjuvant TACE (no/yes) & $<0.001^{\mathrm{a}}$ & $0.331(0.163-0.676)$ & $0.002^{\mathrm{a}}$ \\
\hline
\end{tabular}

${ }^{\mathrm{a}} \mathrm{P}<0.05$. TACE, transcatheter arterial chemoembolization; AFP, $\alpha$-fetoprotein; MO, multicentric occurrence hepatocellular carcinoma; IM, intrahepatic metastases hepatocellular carcinoma; HR, hazard ratio; CI, confidence interval.

A

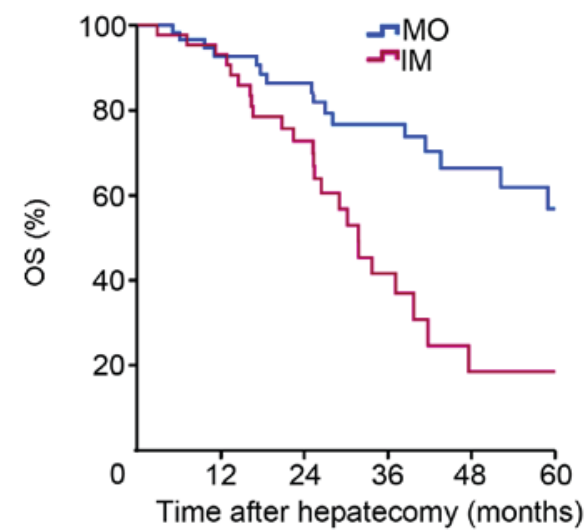

No. at risk

$\begin{array}{ccccccl}\text { MO } & 59 & 54 & 51 & 45 & 39 & 33 \\ \text { IM } & 44 & 41 & 32 & 18 & 8 & 8\end{array}$

B

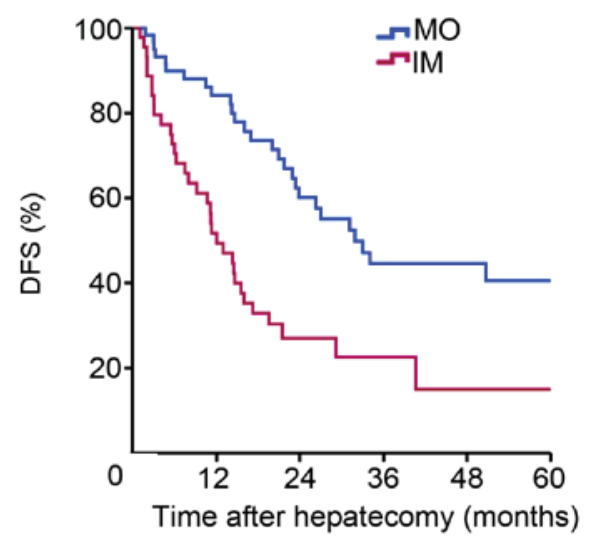

No. at risk

$\begin{array}{llllll}\text { MO 59 } & 49 & 35 & 26 & 26 & 23 \\ \text { IM 44 } & 22 & 13 & 9 & 6 & 6\end{array}$

Figure 2. (A) OS and (B) DFS of patients with MO or IM. (A) $\mathrm{P}=0.001$ and (B) $\mathrm{P}<0.001$ (log-rank test). OS, overall survival; DFS, disease-free survival; MO, multicentric occurrence; IM, intrahepatic metastases.

A

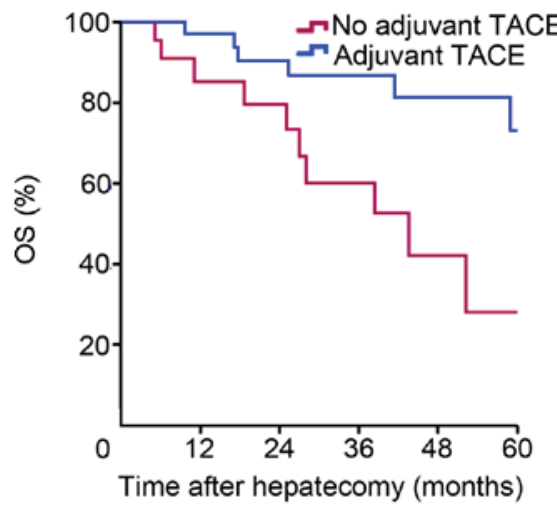

No. at risk

$\begin{array}{llllll}\text { Adjuvant TACE } 37 & 35 & 33 & 32 & 30 & 27\end{array}$

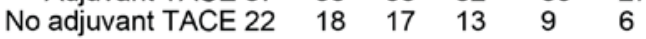

MO group
B

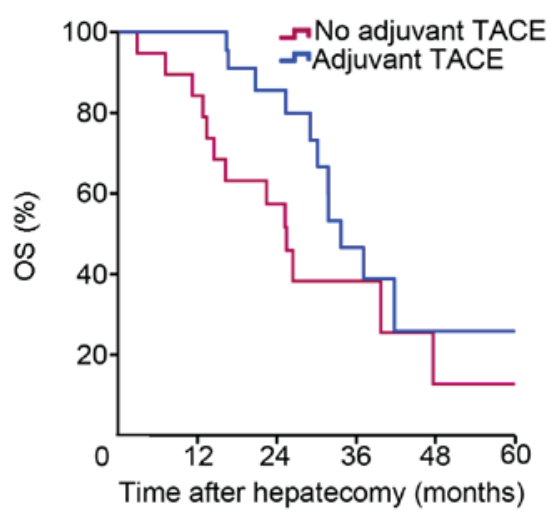

No. at risk

$\begin{array}{cccccc}\text { Adjuvant TACE } 25 & 25 & 21 & 11 & 6 & 6 \\ \text { adjuvant TACE } 19 & 16 & 11 & 7 & 2 & 2\end{array}$

IM group

Figure 3. OS of (A) patients with MO and (B) patients with IM following treatment with HR or HRT. (A) P=0.019 and (B) P=0.132 (log-rank test). TACE, transcatheter arterialV chemoembolization; MO, multicentric occurrence; IM, intrahepatic metastases; HR, hepatic resection; HRT, HR plus adjuvant TACE; OS, overall survival. 
Table IV. Univariate and multivariate Cox proportional hazards regression analyses of factors associated with overall survival of patients $(\mathrm{n}=59)$ with multicentric occurrence hepatocellular carcinoma.

\begin{tabular}{|c|c|c|c|}
\hline \multirow[b]{2}{*}{ Factor } & \multirow{2}{*}{$\frac{\text { Univariate }}{\text { P-value }}$} & \multicolumn{2}{|c|}{ Multivariate analysis } \\
\hline & & $\mathrm{HR}(95 \% \mathrm{CI})$ & P-value \\
\hline Tumor number $(2 />2)$ & 0.264 & & \\
\hline Tumor size $(<50 / \geq 50 \mathrm{~mm})$ & 0.307 & & \\
\hline $\operatorname{AFP}(<100 / \geq 100 \mathrm{ng} / \mathrm{ml})$ & 0.371 & & \\
\hline Microvascular invasion (no/yes) & 0.200 & & \\
\hline Liver cirrhosis (no/yes) & 0.698 & & \\
\hline Adjuvant TACE (no/yes) & $0.026^{\mathrm{a}}$ & $0.300(0.108-0.833)$ & $0.021^{\mathrm{a}}$ \\
\hline
\end{tabular}

${ }^{\mathrm{a}} \mathrm{P}<0.05$. AFP, $\alpha$-fetoprotein; TACE, transcatheter arterial chemoembolization; HR, hazard ratio; CI, confidence interval.

Table V. Subgroup analysis classified by tumor number.

\begin{tabular}{lccc}
\hline Tumor number & $\mathrm{MO}(\mathrm{n}=59)$ & $\mathrm{IM}(\mathrm{n}=44)$ & P-value \\
\hline 2 lesions & 52 & 21 & $<0.001^{\mathrm{a}}$ \\
$>2$ lesions & 7 & 23 & \\
3 lesions & 5 & 8 & \\
4 lesions & 1 & 8 & \\
5 lesions & 1 & 1 & \\
6 lesions & 0 & 8 &
\end{tabular}

${ }^{\mathrm{a}} \mathrm{P}<0.05$. MO, multicentric occurrence hepatocellular carcinoma; IM, intrahepatic metastases hepatocellular carcinoma.
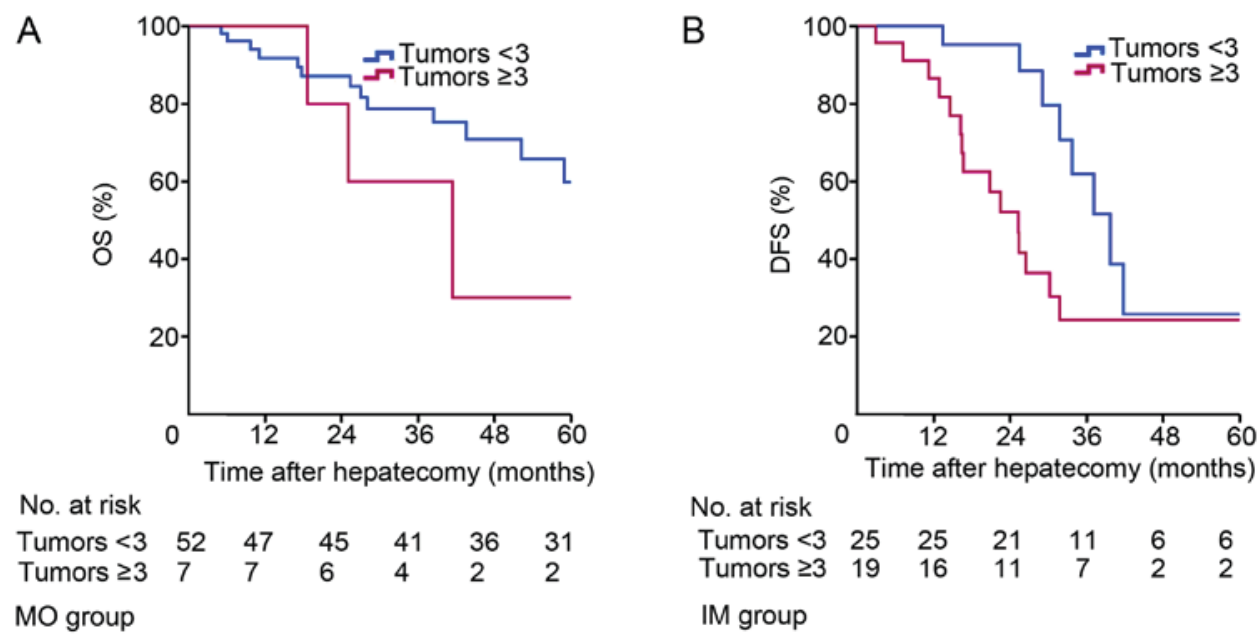

Figure 4. (A) OS of patients with MO with $<3$ or $\geq 3$ tumors following treatment with HRT. (B) DFS of patients with IM with $<3$ or $\geq 3$ tumors following treatment with HRT. (A) $\mathrm{P}=0.300$ and (B) $\mathrm{P}=0.022$ (log-rank test). HRT, hepatic resection plus adjuvant transcatheter arterial chemoembolization; OS, overall survival; DFS, disease-free survival; MO, multicentric occurrence; IM, intrahepatic metastases.

Of the patients with $\mathrm{HCC}, \sim 70 \%$ experience recurrence within 5 years; therefore, reducing the rate of postsurgical recurrence is a key factor in prolonging long-term survival in patients with HCC $(33,34)$. Currently, the accepted method for reducing the recurrence rate of cancer following surgery is adjuvant therapy; however, adjuvant TACE therapy is not recommended for HCC following radical surgery according to the previous guidelines $(6,7)$, as not all patients benefit from it. Previously, a number of studies indicated that adjuvant postsurgical TACE can reduce the postsurgical recurrence rate in high-risk patients with HCC (35-38). Although a randomized controlled trial indicated that postsurgical adjuvant therapy had a minimal effect on outcomes, it was probable that patients with early-stage HCC were included in the study (39). In the 
present study, it was determined that adjuvant TACE was an independent prognostic factor for OS in patients with multifocal HCC; however, it remains unknown if the MO and IM groups can benefit from adjuvant TACE therapy following surgery. A further subgroup analysis demonstrated that postsurgical adjuvant TACE significantly prolonged long-term survival in patients with MO-HCC; however, OS was not significantly prolonged in patients with IM-HCC who underwent adjuvant TACE. Based on these results, patients with MO-HCC should be actively treated with adjuvant TACE to maximize the benefit of surgery. By contrast, since the prognosis of patients with IM-HCC was significantly worse following hepatectomy, postsurgical adjuvant TACE did not result in the same survival benefit for patients with IM-HCC as it did for patients with MO-HCC. Thus, adjuvant TACE may be more beneficial for patients with MO-HCC.

Until now, the BCLC staging system and American Association for the Study of Liver Disease/European Association for the Study of the Liver guidelines classified patients with $>3$ tumors as stage $\mathrm{B}(6,7)$. TACE is recommended for these patients as the first-line treatment; however, in the present study, it was determined that the prognosis of patients with MO-HCC with $\geq 3$ tumors was not worse compared with that of patients with $<3$ tumors following hepatectomy. For the patients with IM-HCC, an increased tumor number indicated a worse prognosis. A previous study demonstrated that the long-term survival rate of patients with MO-HCC following surgical resection was similar to that of patients with single lesions (10). Furthermore, another study indicated that resection may be the treatment of choice for HCC even if patients have $>4$ tumors (40). It is probable that single lesions in MO-HCC originate independently from each other with early stage grading; therefore, even if $>3$ tumors are present, surgical resection is suitable for these patients. However, the lesions are metastases from one lesion in IM-HCC, which are similar to distant metastasis; therefore, an increased number of tumors is indicative of a later stage. Although the study sample was small, the present results indicated that HCC staging should not rely on tumor status alone, and that IM and MO carcinogenesis should also be taken into account. Furthermore, tumor number should not be the primary factor considered when selecting the MO-HCC treatment.

There are a number of limitations to the present study. Firstly, since multinodular HCC with $>3$ tumors or with 2 tumors, 1 of which is $>3 \mathrm{~cm}$, are classified as BCLC stage B, it was controversial to perform surgery. Thus, a limited number of these patients were included in the study, although no less than the number included in previous studies $(12,13)$. Larger cohort studies may be necessary to confirm the results. Secondly, the patients included in the present study were patients with HCC in China, and $92.2 \%$ of patients had HBV-associated HCC. In western countries, the most common causes of HCC are hepatitis $\mathrm{C}$ and alcohol (6). The different etiologies may cause HCC origin differences, and thus affect the ratio of IM and MO. To confirm the conclusions of the present study, further multicenter perspective studies should be performed with a larger cohort.

In conclusion, the present data demonstrated that patients with MO-HCC benefit from HRT, while the same treatment has a minimal effect on the survival of patients with IM-HCC.
Accordingly, liver resection plus TACE is recommended for MO-HCC, and TACE, targeted drugs or other palliative treatment should be considered for IM-HCC. Prospective multicenter studies with a larger sample are required in the future to further confirm the present results.

\section{Acknowledgements}

Not applicable.

\section{Funding}

This study was funded by grants from the Chinese State Key Project for Basic Research (973) (no. 2014CBA02001).

\section{Availability of data and materials}

The datasets used or analyzed during the current study are available from the corresponding author on reasonable request.

\section{Authors' contributions}

DX, XL and BX participated in the design of the study. DX and LW collected the data. DX and XL analyzed and interpreted the data. DX, XL and BX prepared the manuscript. All authors read and approved the final manuscript.

\section{Ethics approval and consent to participate}

The study was approved by the Ethics Committee of Beijing Cancer Hospital.

\section{Patient consent for publication}

Informed consent statement: Patients were not required to give informed consent to the study, as the analysis used anonymous clinical data that were obtained after each patient agreed to treatment by verbal consent. Individuals cannot be identified according to the data presented.

\section{Competing interests}

The authors declare that they have no competing interests.

\section{References}

1. Maluccio M and Covey A: Recent progress in understanding, diagnosing, and treating hepatocellular carcinoma. CA Cancer J Clin 62: 394-399, 2012.

2. Jemal A, Bray F, Center MM, Ferlay J, Ward E and Forman D: Global cancer statistics. CA Cancer J Clin 61: 69-90, 2011.

3. Zhong JH, Ke Y, Gong WF, Xiang BD, Ma L, Ye XP, Peng T, Xie GS and Li LQ: Hepatic resection associated with good survival for selected patients with intermediate and advanced-stage hepatocellular carcinoma. Ann Surg 260: 329-340, 2014.

4. Torzilli G, Belghiti J, Kokudo N, Takayama T, Capussotti L, Nuzzo G, Vauthey JN, Choti MA, De Santibanes E, Donadon M, et al: A snapshot of the effective indications and results of surgery for hepatocellular carcinoma in tertiary referral centers: Is it adherent to the EASL/AASLD recommendations?: An observational study of the HCC East-West study group. Ann Surg 257: 929-937, 2013. 
5. Hsu CY, Liu PH, Hsia CY, Lee YH, Nagaria TS, Lee RC, Lin HC and Huo TI: Surgical resection is better than transarterial chemoembolization for patients with hepatocellular carcinoma beyond the milan criteria: A prognostic nomogram study. Ann Surg Oncol 23: 994-1002, 2016.

6. European Association For The Study Of The Liver; European Organisation For Research And Treatment Of Cancer: EASL-EORTC clinical practice guidelines: Management of hepatocellular carcinoma. J Hepatol 56: 908-943, 2012.

7. Bruix J and Sherman M; American Association for the Study of Liver Diseases: Management of hepatocellular carcinoma: An update. Hepatology 53: 1020-1022, 2011.

8. Kudo M, Izumi N, Kokudo N, Matsui O, Sakamoto M, Nakashima O, Kojiro M and Makuuchi M; HCC Expert Panel of Japan Society of Hepatology: Management of hepatocellular carcinoma in Japan: Consensus-based clinical practice guidelines proposed by the Japan society of hepatology (JSH) 2010 updated version. Dig Dis 29: 339-364, 2011.

9. Feo F and Pascale RM: Multifocal hepatocellular carcinoma: Intrahepatic metastasis or multicentric carcinogenesis? Ann Transl Med 3: 4, 2015

10. Yasui M, Harada A, Nonami T, Takeuchi Y, Taniguchi K, Nakao A and Takagi H: Potentially multicentric hepatocellular carcinoma: Clinicopathologic characteristics and postoperative prognosis. World J Surg 21: 860-865, 1997.

11. Shimada M, Hamatsu T, Yamashita Y, Rikimaru T, Taguchi K, Utsunomiya T, Shirabe K and Sugimachi K: Characteristics of multicentric hepatocellular carcinomas: Comparison with intrahepatic metastasis. World J Surg 25: 991-995, 2001.

12. Wang J, Li Q, Sun Y, Zheng H, Cui Y, Li H, Zhou H and Hao X: Clinicopathologic features between multicentric occurence and intrahepatic metastasis of multiple hepatocellular carcinomas related to HBV. Surg Oncol 18: 25-30, 2009.

13. Li SL, Su M, Peng T, Xiao KY, Shang LM, Xu BH, Su ZX, Ye XP, Peng N, Qin QL, et al: Clinicopathologic characteristics and prognoses for multicentric occurrence and intrahepatic metastasis in synchronous multinodular hepatocellular carcinoma patients. Asian Pac J Cancer Prev 14: 217-223, 2013.

14. Sun JJ, Wang K, Zhang CZ, Guo WX, Shi J, Cong WM, Wu MC, Lau WY and Cheng SQ: Postoperative adjuvant transcatheter arterial chemoembolization after R0 hepatectomy improves outcomes of patients who have hepatocellular carcinoma with microvascular invasion. Ann Surg Oncol 23: 1344-1351, 2016.

15. Dong ZR, Zhang PF, Wang CH, Zhang C, Cai JB, Shi GM Ke AW, Sun HC, Qiu SJ, Zhou J and Fan J: Postoperative adjuvant transcatheter arterial chemoembolization for resectable multiple hepatocellular carcinoma beyond the Milan criteria: A retrospective analysis. Am J Cancer Res 5: 450-457, 2014.

16. Liu C, Sun L, Xu J and Zhao Y: Clinical efficacy of postoperative adjuvant transcatheter arterial chemoembolization on hepatocellular carcinoma. World J Surg Oncol 14: 100, 2016.

17. Takenaka K, Adachi E, Nishizaki T, Hiroshige K, Ikeda T, Tsuneyoshi M and Sugimachi K: Possible multicentric occurrence of hepatocellular carcinoma: A clinicopathological study. Hepatology 19: 889-894, 1994.

18. Liver Cancer Study Group of Japan: Primary liver cancer in Japan. Clinicopathologic features and results of surgical treatment. Ann Surg 211: 277-287, 1990.

19. Matsumoto Y, Fujii H, Matsuda M and Kono H: Multicentric occurrence of hepatocellular carcinoma: Diagnosis and clinical significance. J Hepatobiliary Pancreat Surg 8: 435-440, 2001

20. Rahbari NN, Garden OJ, Padbury R, Brooke-Smith M, Crawford M, Adam R, Koch M, Makuuchi M, Dematteo RP, Christophi C, et al: Posthepatectomy liver failure: A definition and grading by the International Study Group of Liver Surgery (ISGLS). Surgery 149: 713-724, 2011.

21. Oikawa T, Ojima H, Yamasaki S, Takayama T, Hirohashi S and Sakamoto M: Multistep and multicentric development of hepatocellular carcinoma: Histological analysis of 980 resected nodules. J Hepatol 42: 225-229, 2005.

22. Ng IO, Guan XY, Poon RT, Fan ST and Lee JM: Determination of the molecular relationship between multiple tumour nodules in hepatocellular carcinoma differentiates multicentric origin from intrahepatic metastasis. J Pathol 199: 345-353, 2003.

23. Chan AC, Chan SC, Chok KS, Cheung TT, Chiu DW, Poon RT, Fan ST and Lo CM: Treatment strategy for recurrent hepatocellular carcinoma: Salvage transplantation, repeated resection, or radiofrequency ablation? Liver Transpl 19: 411-419, 2013.
24. Gluer AM, Cocco N, Laurence JM, Johnston ES, Hollands MJ, Pleass HC, Richardson AJ and Lam VW: Systematic review of actual 10-year survival following resection for hepatocellular carcinoma. HPB (Oxford) 14: 285-290, 2012.

25. Hasegawa K, Kokudo N, Makuuchi M, Izumi N, Ichida T, Kudo M, Ku Y, Sakamoto M, Nakashima O, Matsui O and Matsuyama Y: Comparison of resection and ablation for hepatocellular carcinoma: A cohort study based on a Japanese nationwide survey. J Hepatol 58: 724-729, 2013.

26. Bolondi L, Burroughs A, Dufour JF, Galle PR, Mazzaferro V, Piscaglia F, Raoul JL and Sangro B: Heterogeneity of patients with intermediate (BCLC B) Hepatocellular Carcinoma: Proposal for a subclassification to facilitate treatment decisions. Semin Liver Dis 32: 348-359, 2012.

27. Xue R, Li R, Guo H, Guo L, Su Z, Ni X, Qi L, Zhang T, Li Q, Zhang $\mathrm{Z}$, et al: Variable intra-tumor genomic heterogeneity of multiple lesions in patients with hepatocellular carcinoma. Gastroenterology 150: 998-1008, 2016.

28. Miao R, Luo H, Zhou H, Li G, Bu D, Yang X, Zhao X, Zhang H, Liu S, Zhong Y, et al: Identification of prognostic biomarkers in hepatitis B virus-related hepatocellular carcinoma and stratification by integrative multi-omics analysis. J Hepatol 61: 840-849, 2014.

29. Kumada T, Nakano S, Takeda I, Sugiyama K, Osada T, Kiriyama S, Sone Y, Toyoda H, Shimada S, Takahashi M and Sassa T: Patterns of recurrence after initial treatment in patients with small hepatocellular carcinoma. Hepatology 25: 87-92, 1997.

30. Yamamoto T, Kajino K, Kudo M, Sasaki Y, Arakawa Y and Hino O: Determination of the clonal origin of multiple human hepatocellular carcinomas by cloning and polymerase chain reaction of the integrated hepatitis B virus DNA. Hepatology 29: 1446-1452, 1999.

31. Morimoto O, Nagano H, Sakon M, Fujiwara Y, Yamada T, Nakagawa $\mathrm{H}$, Miyamoto A, Kondo M, Arai I, Yamamoto T, et al: Diagnosis of intrahepatic metastasis and multicentric carcinogenesis by microsatellite loss of heterozygosity in patients with multiple and recurrent hepatocellular carcinomas. J Hepatol 39: 215-221, 2003.

32. Kim PT, Jang JH, Atenafu EG, Fischer S, Greig PD, McGilvray ID, Wei AC, Gallinger S and Cleary SP: Outcomes after hepatic resection and subsequent multimodal treatment of recurrence for multifocal hepatocellular carcinoma. Br J Surg 100: 1516-1522, 2013.

33. Taura K, Ikai I, Hatano E, Fujii H, Uyama N and Shimahara Y: Implication of frequent local ablation therapy for intrahepatic recurrence in prolonged survival of patients with hepatocellular carcinoma undergoing hepatic resection: An analysis of 610 patients over 16 years old. Ann Surg 244: 265-273, 2006.

34. Poon RT, Fan ST, Lo CM, Ng IO, Liu CL, Lam CM and Wong J: Improving survival results after resection of hepatocellular carcinoma: A prospective study of 377 patients over 10 years. Ann Surg 234: 63-70, 2001.

35. Llovet JM and Bruix J: Systematic review of randomized trials for unresectable hepatocellular carcinoma: Chemoembolization improves survival. Hepatology 37: 429-442, 2003.

36. Llovet JM, Real MI, Montana X, Planas R, Coll S, Aponte J, Ayuso C, Sala M, Muchart J, Solà R, et al: Arterial embolisation or chemoembolisation versus symptomatic treatment in patients with unresectable hepatocellular carcinoma: A randomised controlled trial. Lancet 359: 1734-1739, 2002.

37. Lo CM, Ngan H, Tso WK, Liu CL, Lam CM, Poon RT, Fan ST and Wong J: Randomized controlled trial of transarterial lipiodol chemoembolization for unresectable hepatocellular carcinoma. Hepatology 35: 1164-1171, 2002.

38. Cheng X, Sun P, Hu QG, Song ZF, Xiong J and Zheng QC: Transarterial (chemo)embolization for curative resection of hepatocellular carcinoma: A systematic review and meta-analyses. J Cancer Res Clin Oncol 140: 1159-1170, 2014.

39. Yin L, Li H, Li AJ, Lau WY, Pan ZY, Lai EC, Wu MC and Zhou WP: Partial hepatectomy vs. transcatheter arterial chemoembolization for resectable multiple hepatocellular carcinoma beyond Milan Criteria: A RCT. J Hepatol 61: 82-88, 2014.

40. Nojiri K, Tanaka K, Takeda K, Ueda M, Matsuyama R, Taniguchi K, Kumamoto T, Mori R and Endo I: The efficacy of liver resection for multinodular hepatocellular carcinoma. Anticancer Res 34: 2421-2426, 2014

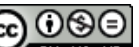

This work is licensed under a Creative Commons Attribution-NonCommercial-NoDerivatives 4.0 International (CC BY-NC-ND 4.0) License. 